\title{
Simulation of Spatially Varying Ground Motions at Site with Stochastic Soil Layers: A Case Study in Nw Algeria
}

\author{
Karim Afif Chaouch \\ Ecole Polytechnique d'Architecture et d'Urbanisme \\ Route de beaulieu, B.P N${ }^{\circ} 177,16200$, El Harrach, Algiers, Algeria \\ karim.afifchaouch@gmail.com \\ National Polytechnic School, Seismic Engineering and Structural Dynamics Laboratory \\ 10 Rue des Frères OUDEK, 16200, El Harrach \\ Algiers, Algeria \\ karim.afifchaouch@gmail.com
}

\begin{abstract}
Seismic design of common engineering structures is based on the assumption that excitations at all support points are uniform or fully coherent. However, in lifeline structures with dimensions of the order of wavelengths of incident seismic waves, spatial variation of seismic ground motions caused by incoherence effects and stochasticity in the characteristics of the surface layers may introduce significant additional forces in their structural elements. The physical characterization of the seismic spatial variation and the realistic simulation of the spatially variable ground motion random field become then vital to the success of performance-based design of these extended structures. This paper presents simulation of spatially varying earthquake motions at the free surface of a homogeneous layered stochastic soil site in the epicentral region of the El-Asnam Earthquake in Algeria, considering incoherence, wave passage and site effects. Lagged coherency functions at bedrock have been estimated by simulating ground motion field (around Sogedia Factory) corresponding to the 1980 El-Asnam Earthquake. Considering randomness in the thickness of soil layers overlying the bedrock in the study area, an analytical approach has been used to evaluate lagged coherency functions at the surface. Soil proprieties are assumed to vary laterally with a Gaussian distribution. The critical parameter controlling wave passage effect is the apparent propagation velocity of shear waves across the array and is estimated by using frequency-wave number spectrum analysis. It is observed that the simulated spatially variable surface ground-motion time histories at different locations are compatible with the properties of the target (predictive) random field, i.e. assumption of site homogeneity by conserving the same energy as the reference surface motion and its model of spatial coherency function.
\end{abstract}

Keywords: Ground motion simulation; ground motion spatial variation; random soil

\section{Introduction}

Spatially varying ground motions (SVGMs), exhibiting spatial differences in their amplitude and phases, have a significant effect on the responses of spatially extended structures (e.g., Walling and Abrahamson [1]), such as Nuclear Power Plant (NPP) structures, where the nonlinear structural response history analysis necessitates the synthesis of SVGMs, as well as other lifeline structures. In order to consider such effects, time domain dynamic analysis is increasingly performed for the seismic design of extended structures. As a result, spatially variable ground motion time histories are required as an input at different locations along the structure. Efficiently and rationally generating asynchronous motions is an important issue in modern earthquake engineering practice. Several stochastic methods of simulation, unconditional or conditional, have been developed to generate spatially correlated ground motions given an empirical coherency function (see, for example, [2] and [3]).

Hao's method [2], one of the pioneering methods in the field and which represents a significant contribution to modern earthquake engineering, has certain limitations that were identified, including: (1) the lack of energy conservation of generated motions across stations, (2) distortion of generated motion due to wave passage effect only, and (3) the inability to use general forms of incoherence functions. The method proposed by Abrahamson [3] overcomes these limitations and is thus more suitable for use in generation of incoherent ground motion for the nonlinear dynamic analysis of extended structures especially where general forms of incoherence functions are employed. 
The spatial variation of seismic motions generated at multiple stations is controlled by two major functions, coherency and apparent velocity. Several generic models of lagged coherency (random phase variability), which can be classified as empirical, semi-empirical, analytical, and theoretical models, have been proposed in the literature. Most of the coherency models used in these methods of simulations are derived or regressed from strong motion data recorded by dense arrays such as the El-Centro array in California, the SMART-1 strong motion array in Taiwan, and the Parkway Valley array in New Zealand (see, for example, [4]). It is well known that coherency models calibrated from data collected in one region may not be suitable for use in other areas (see, for example, [5]; [6]; [7]; [8]). Despite this, due to lack of local data, which is the case in the current study area (epicentral region of the 1980 El-Asnam Earthquake in northwest Algeria), coherency models calibrated for one region are often used to simulate ground motion in other regions, sometimes with different tectonic and geological settings. Also, cconsequently of these difficulties and in the absence of the records, the apparent propagation velocity of the motions is given some approximate values (ranging from low values of a few hundred to infinity), and the excitations are assumed, as for uniform sites, to propagate from one end of the bridge structure to the other. Clearly, this may lead to a significant variability in the response of structures, particularly the ones located at sites with soft soil conditions, due to the significant uncertainty in the evaluation of this quantity.

In this context, AfifChaouch et al. [9] presented an extension of the finite-source Empirical Green's Function (EGF) method of Irikura et al. [10] to synthesize SVGMs and thereby estimate lagged coherency functions at the bedrock of the study area. Based on simulated motion, a parametric model of lagged coherency at bedrock was also presented by AfifChaouch et al. [9]. Then, AfifChaouch et al. [11] extended the work presented in [9] using the method of Zerva and Harada [12] to investigate the effects of lateral soil hererogeneity in lagged coherency of strong ground motion for the case of the Sogedia site in El-Asnam city located in the epicentral region of the 1980 El-Asnam Earthquake. Due to the lack of sufficient information to describe lateral variability soil mechanical properties, only randomness in the thickness of the different layers were modelled. They thus obtained the total lagged coherency functions at the ground surface, which can now be used to simulate spatially variable surface motion for engineering applications.

In this paper, we continue their study presented in [11] to simulate spatially variable ground motions at the surface of the same random site of Sogedia using the conditional simulation method of Abrahamson [3]. For this, the total lagged coherency function obtained in [11] is considered as modelling the incoherence effect and, the wave passage effect is modelled here by an apparent wave velocity estimated by using frequency-wave number spectrum analysis.

\section{Spatial Coherency Function At Homogeneous Stochastic Horizontal Ground}

Spatial variability of ground motion is caused by a number of factors (Der Kiureghian [13]). Assuming homogenous site conditions, SVGM are caused by the wave passage effect and incoherence effect. The wave passage is time delays in wave arrivals due to inclined vertically propagating plane waves or horizontally propagating surface waves. The incoherence effect is caused by complex waveform scattering occurs as the seismically generated body waves encounter heterogeneities along their source-to-site travel path.

Consider stochastic soil layers resting on rigid bedrock and subjected to earthquake ground motion, the complex coherency function of surface motion is composed of terms corresponding to wave passage effects, bedrock motion loss of coherency effects, and site response contribution [12], expressed as (see, for example, [12]; [13]):

$$
\gamma(\xi, \omega)=\gamma_{b, c o h}(\xi, \omega) \cdot \gamma_{b, p r o p}(\xi, \omega) \cdot \gamma_{l, c o h}(\xi, \omega)
$$

where $\gamma_{b, p r o p}(\xi, \omega)$ is lagged coherency function of bedrock motion. In this work, this function is parametrized by the following Hindy and Novak model [14] for which the parameters were calibrated from lagged coherency functions estimated from ground motion simulated at the bedrock of the epicentral region of the 1980 El-Asnam Earthquake by the widely used finite-source ground motion simulation approach, the so-called Empirical Green's Function (EGF) method.

$$
\gamma_{b, c o h}(\xi, \omega)=\exp \left\{-(\alpha \omega \xi)^{\lambda}\right\}
$$


The $\gamma_{l, c o h}(\xi, \omega)$ represents the contribution of the soil stochasticity to the lagged coherency of surface motions, and is given by [11]:

$$
\gamma_{l, \text { coh }}=\frac{H_{1}\left(\beta, \omega_{0}, \zeta_{0}, \omega\right)+R_{\omega \omega}(\xi) \cdot H_{2}\left(\beta, \omega_{0}, \zeta_{0}, \omega\right)}{H_{1}\left(\beta, \omega_{0}, \zeta_{0}, \omega\right)+\sigma_{\omega \omega}^{2}(\xi) \cdot H_{2}\left(\beta, \omega_{0}, \zeta_{0}, \omega\right)}
$$

where the participation factor $\beta$, the mean value $\omega_{0}$ and standard deviations $\sigma_{\omega \omega}$ and autocorrelation $R_{\omega \omega}$ of the predominant natural frequency of the ground, and its equivalent damping ratio $\zeta_{0}$ are all the parameters of the proposed model of Zerva and Harada [12] and depend on soil type. The analytic expressions of the functions $H_{1}$ and $H_{2}$ are given in [11]. The overall incoherence (incident motion incoherence and soil layer stochasticity) in the spatial variation of the surface motions is given by:

$$
\gamma_{c o h}(\xi, \omega)=\gamma_{b, c o h}(\xi, \omega) \cdot \gamma_{l, c o h}(\xi, \omega)
$$

The $\gamma_{b, p r o p}(\xi, \omega)$ is a term describing the wave passage effect is given by

$$
\gamma_{b, p r o p}(\xi, \omega)=\exp \{-i \omega \xi / c\}
$$

To capture the wave passage effect, one needs the information of the apparent wave velocity $v_{a p p}$ in the direction of propagation and the fault-structure geometry. The required parameter $c$ is the apparent wave velocity along the structure axis and can be written as $c=v_{a p p} / \sin \theta$, in which $\theta$ is the angle between the line perpendicular to the structure axis (along a line connecting all the stations) and the direction of propagation of the incoming waves. The $v_{a p p}$ and back-azimuth direction $B a z$ (direction of approach of the wavefront) corresponding to the 1980 El-Asnam Earthquake are estimated herein by using frequency-wave number spectrum analysis. It should be noted that the apparent propagation effects (deterministic phase variations caused by the wave passage effect) of the surface motions is controlled by that of the incident motion in the bedrock, since vertical propagation is considered within the layer in the Zerva and Harada model.

\section{Abrahamson's Method}

The Abrahamson [3] method assumes that the Fourier amplitude of the motion at each station is equal to the Fourier amplitude of the given reference motion. The difference in the Fourier phase between two stations is due to stochastic variation in the phase, which can be quantified by lagged coherency function. Derived from the relation between the lagged coherency and statistical properties of the Fourier phase angles, the coherent ground motion generation is only adjusting phase angle to match the specified lagged coherency function. In this method the Fourier phase angle of a given reference motion are used instead of an arbitrary random phase angle. The wave passage effect is included by applying systematic linear phase shifts in the frequency domain to the stationary time histories generated by this method. More details are given in [3].

To model the temporal variation of the simulated ground motions, the simulated stationary time histories are multiplied by the Jennings et al. [15] envelope function, with $t_{0}$ and $t_{n}$ were used, so that the flat part of the envelop function, or, equivalently, the strong motion duration of the series, is $t_{n}-t_{0}$.

\section{Numerical Example}

A numerical example is presented to simulate non-stationary ground motion time histories using the Abrahamson algorithm at different locations on the ground surface of a stochastic site with multiple soil layers. For this we consider the Sogedia site in El-Asnam city. The soil conditions at the site are shown in Figs. 1-(a) and 1-(b), over a length of 1200m. The material properties are given in the below Fig. 1-(a) and Table 1 in [11], respectively, represent mean values (expected values). Due to lack of data, it is assumed that stochasticity in soil characteristics is due to the variability in the depth of the 
layers. A Gaussian distribution is assumed for layer thickness with a $20 \%$ coefficient of variation. The bedrock is assumed to be rigid. The ground is uniformly divided into sixty $20 \mathrm{~m}$ sections.

In the present example of the Sogedia soil profil, we generate transverse component of accelerations on ground surface at five $(n=5)$ locations (stations), namely $\mathrm{S}^{(0)}, \mathrm{S}^{(1)}, \mathrm{S}^{(2)}, \mathrm{S}^{(3)}$ and $\mathrm{S}^{(4)}$. Station $\mathrm{S}^{(0)}$, which corresponds to the projection on the surface of the station $S^{\prime(0)}$ at the rock, is considered as the reference station and located at $X=0$ in the Fig. 1-(a); the other stations are separated from it by $40 \mathrm{~m}, 100 \mathrm{~m}, 200 \mathrm{~m}$, and $500 \mathrm{~m}$. Epicentral distance of the surface reference station is $5 \mathrm{~km}$. Simulation of ground motion and estimation of all lagged coherencies were performed by computer codes developed by the author.

\begin{tabular}{|c|}
\hline $\begin{array}{c}\text { No.1 Clayey mixture } \\
(\text { thickness }=11 \mathrm{~m})\end{array}$ \\
\hline $\begin{array}{c}\text { No.2 Sandstone clay and sand } \\
\text { (thickness }=22 \mathrm{~m})\end{array}$ \\
\hline
\end{tabular}

(a)

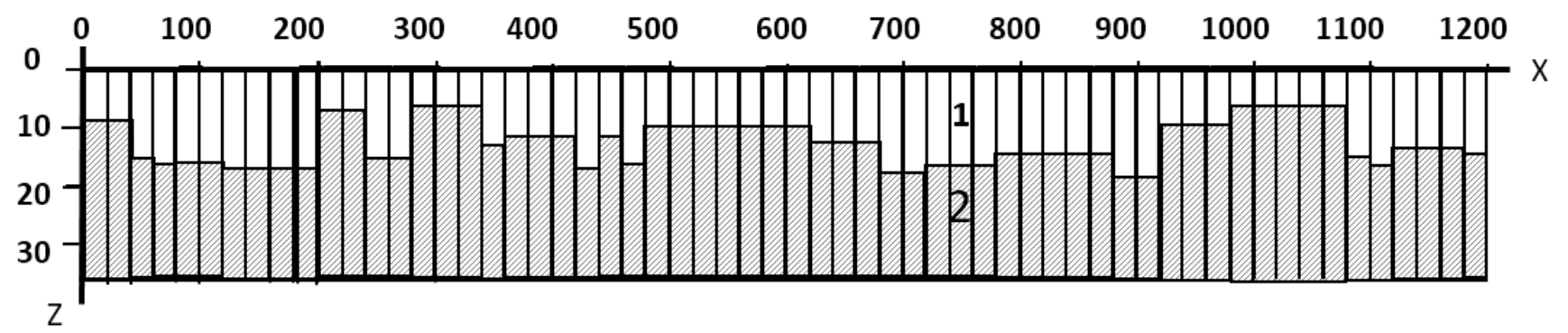

(b)

Fig. 1: (a) Site profile at Sogedia Factory in northwest Algeria with mean layer thicknesses, and (b) a realization of the soil profile (bedrock not shown) with stochastic layer thickness.

Using the estimated parameters values given in [11] of $\alpha=5.8710^{-5}, \lambda=1.52$ (of $\gamma_{b, c o h}(\xi, \omega)$ in Eq. 2) and $\omega_{0}=$ $9.6 \pi \mathrm{rad} / \mathrm{s}\left(f_{0}=4.8 \mathrm{~Hz}\right), \sigma_{\omega \omega}=0.06, R_{\omega \omega}(\xi), \zeta_{0}=5 \%$ and $\beta=4 / \pi$ (of $\gamma_{l, c o h}(\xi, \omega)$ in Eq. 3), the overall lagged coherency $\gamma_{c o h}(\xi, \omega)$ (Eq. 4) at the surface was estimated, and is presented in Fig. 2. The lagged coherency functions exhibit a sharp decrease near the fundamental frequency of the site $\omega_{0}$ that is caused by the random variability around its mean value for the different "soil columns" at the site. 


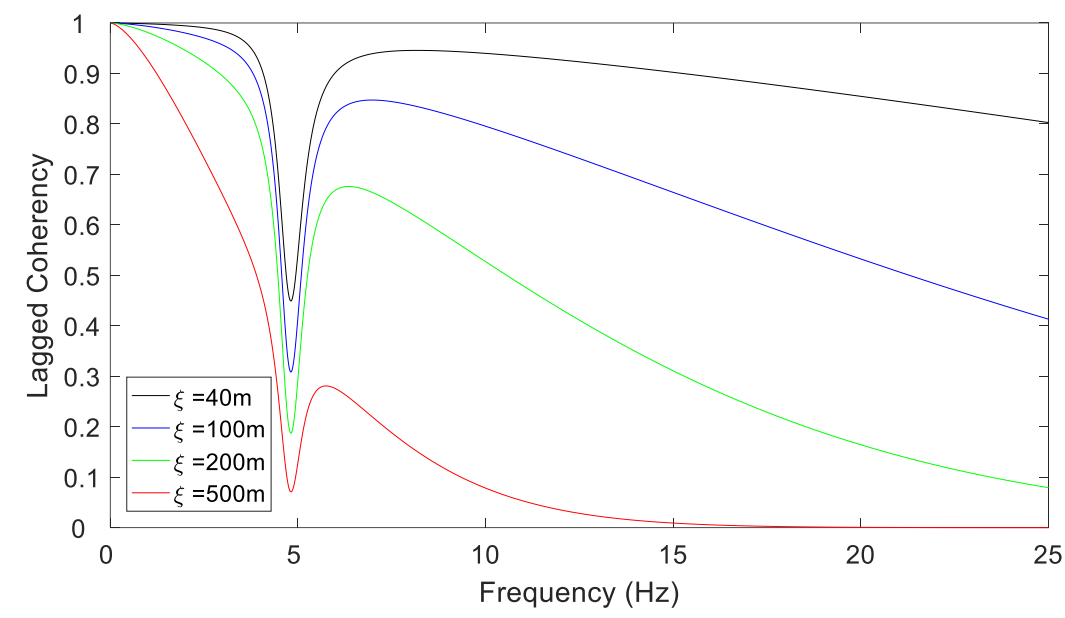

Fig. 2: Lagged coherency function at the surface; obtained by Eq. (4) from bedrock coherency function

(Hindy and Novak model, Eq. 2) and the contribution of stochastic site (Eq. 3).

In this study, a bedrock multiple-station 2-D generic array centred $5 \mathrm{~km} \mathrm{~N} 265^{\circ} \mathrm{W}$ of the epicentre of the October 10 $1980 M_{s}=7.2$ Earthquake occurred in El-Asnam region (North-West Algeria) (see Fig. 2 in [9]), is considered to simulate at 37 stations the NS component time-series using the finite-source Empirical Green's Function (EGF) method of Irikura et al. [10]. This simulation is carried out by the widely used finite-source

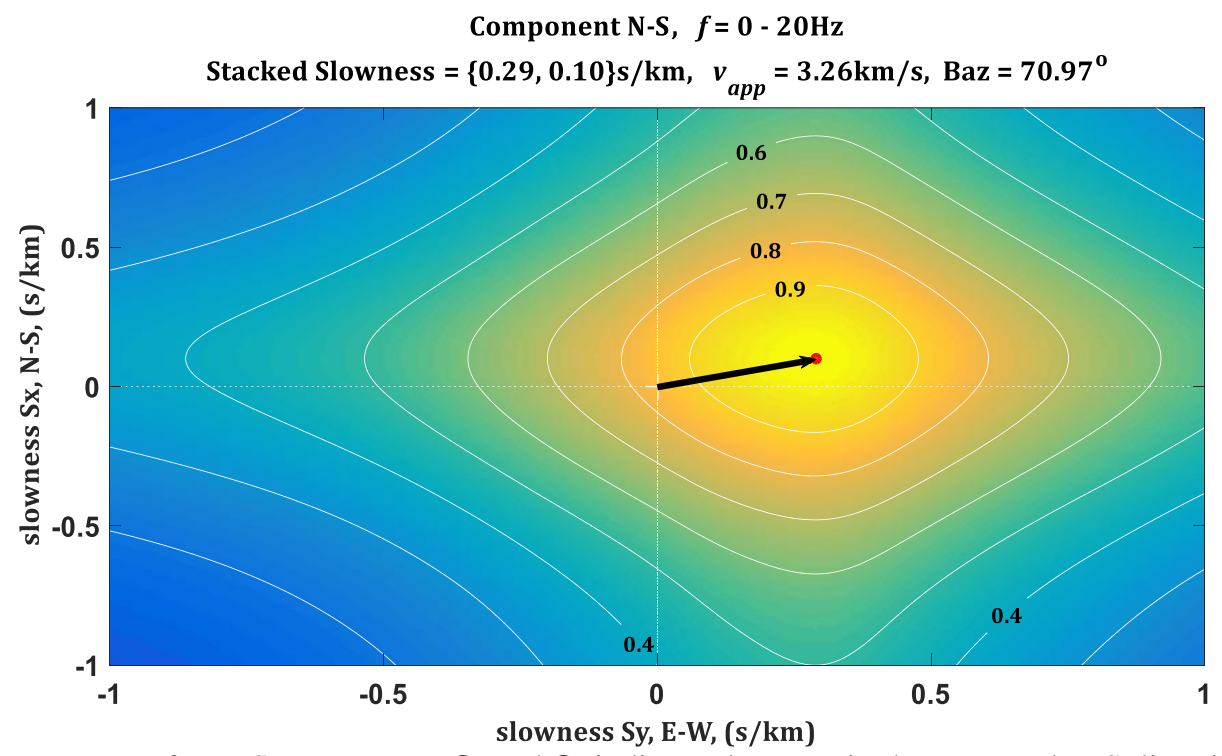

Fig. 3: Stacked slowness spectrum for N-S component. $S_{x}$ and $S_{y}$ indicate slowness in the E-W and N-S directions respectively. The F$\mathrm{K}$ spectral values computed in the frequency range of $0-20 \mathrm{~Hz}$ are normalized by the largest value obtained for each frequency. The estimated direction to the source (back-azimuth direction) is indicated by the black arrow. The corresponding apparent propagation velocity and the back-azimuth are printed on the title of the plot.

ground motion simulation approach, the so-called Empirical Green's Function (EGF) method. Based on a frequency-wave number spectrum (F-K) and the stacked slowness spectra (SS) [16] analysis applied to the N-S component, apparent velocity $v_{a p p}$ and back-azimuth direction (clockwise from north) Baz of the single plane wave dominating the motions are identified 
and estimated to $v_{a p p}=3.26 \mathrm{~km} / \mathrm{s}$ and $\mathrm{Baz}=71^{0}$. The stacked slowness spectrum for the NS component is shown in Fig. 3. The site's X-axis, containing the stations in Fig. 1-(b), is oriented with an angle of $265^{\circ}$ (clockwise from north) and using the two estimated values of $v_{a p p}$ and $B a z$, the required apparent velocity $c\left(c=v_{a p p} / \sin \theta\right)$ along the $\mathrm{x}$-axis to introduce the wave passage effect (Eq. 5) in the simulation is then equal to $3.36 \mathrm{~km} / \mathrm{s}$.

In addition of the overall lagged coherency $\gamma_{c o h}(\xi, \omega)$ and wave passage $\gamma_{b, p r o p}(\xi, \omega)$ functions, the reference surface motion at the station $S^{(0)}$ needed in the above Abrahamson method of simulation is obtained by convolution at the top of the site of the generated motion at the rock station $S^{\prime(0)}$ by [9] using the equivalent linear transfer function of the site estimated in [11].The parameters of the Jennings envelope function are with $t_{0}=2 \mathrm{~s}$ and $t_{n}=15 \mathrm{~s}$ given in [9]. The generated transverse surface motions at the five stations using the Abrahamson method are shown in Fig. 4. The corresponding 5\% damped acceleration response spectra and arias intensity [17] are shown in Fig. 5. Figure 6 is the comparison represented in the hyperbolic arctangent $\left(\tanh ^{-1}\right)$ space of the lagged coherencies computed by means of signal processing (as described in Sect. 2 in [9]) between the generated ground motion time histories (Fig. 4) and the prescribed model (Eq. 4, Fig. 2).

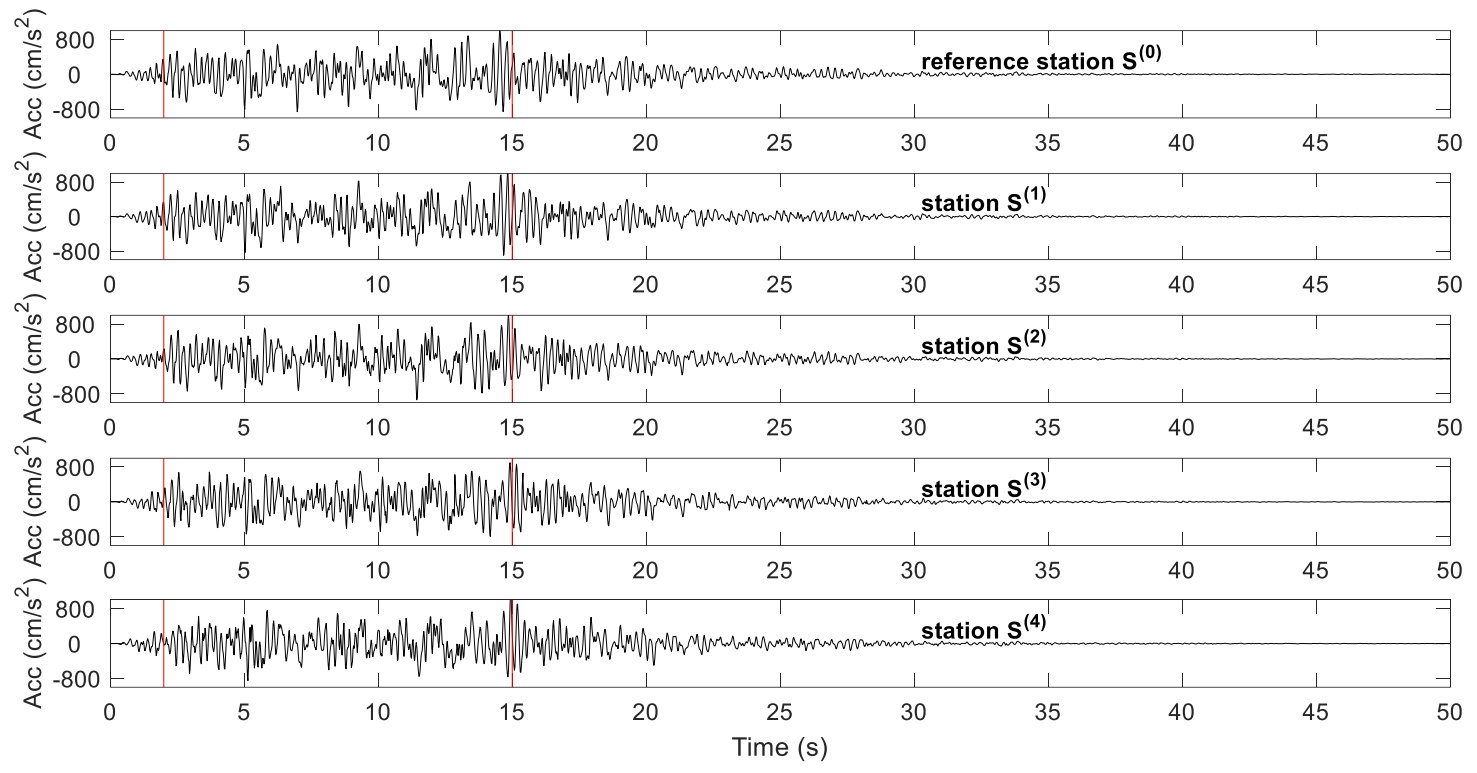

Fig. 4: Transverse component of ground acceleration simulated at the five stations. Time window between the red lines are used to compute lagged coherencies shown in Fig. 6.

As we can see in the above figures, the simulated spatially variable surface ground-motion time histories at different locations conserve the same energy and their response spectra (i.e. power spectral densities) are close to that of the reference motion, and therefore the assumption of the considered homogeneous soil site is preserved by the used Abrahamson method. A good match can also be observed between the coherency loss functions computed from the simulated motions (Fig. 4) and the overall incoherence model $\gamma_{c o h}(\xi, \omega)$ (Eq. 4). It is then proven that the simulated spatial ground motion time histories are compatible with the target model of coherency loss function. In the absence of data record, the generated time histories can be used as inputs to multiple supports of long span structures crossing random site. 

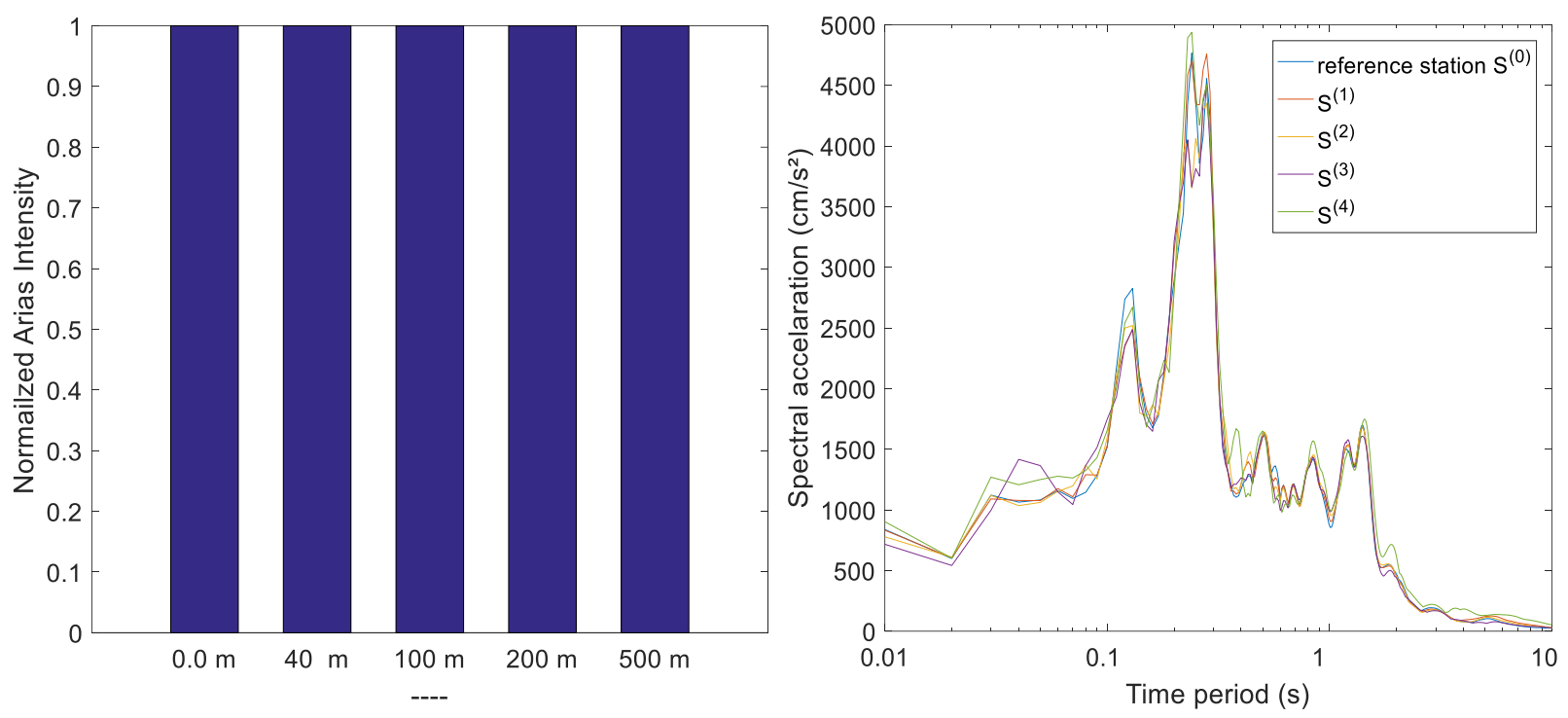

Fig. 5: Response spectra (right) and normalized arias intensity (left) of generated motions at different stations shown in Fig. 4,
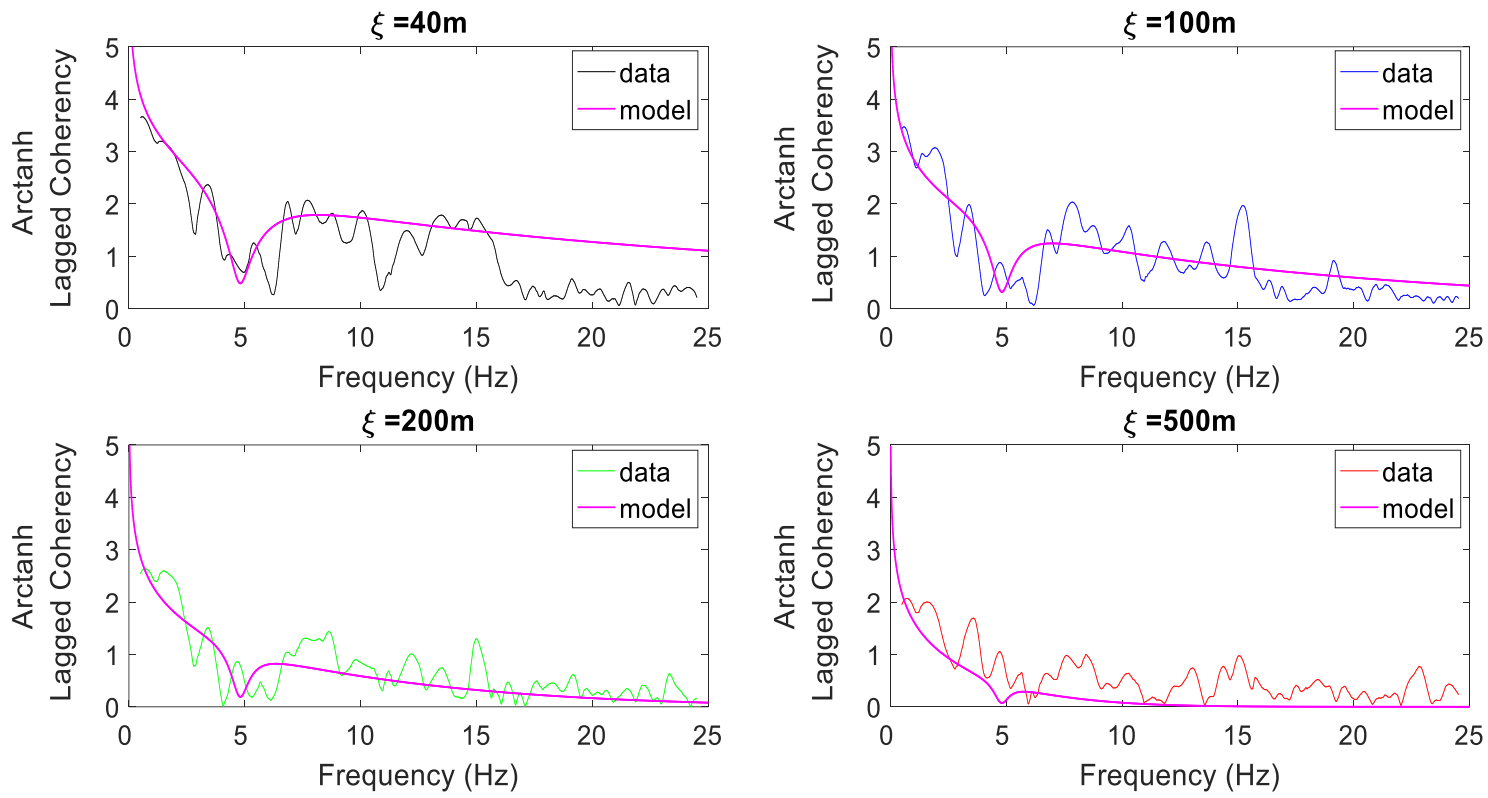

Fig. 6: Comparison of coherency loss computed between the generated surface accelerations with model coherency loss function (Eq. 4, Fig. 2).

\section{Conclusions}

This paper presents a simulation of spatially varying earthquake ground motions on surface of a typical random site in the epicentral area of the 1980 El-Asnam Earthquake in northwest Algeria. The study is based on lagged coherency of bedrock ground motion estimated from ground motion field simulated by using the Empirical Green's Function method, the contribution of random homogeneous site to the surface lagged coherency and the apparent wave velocity of shear waves 
across the study area during this earthquake. The common technique of Abrahamson for generating spatially variable ground motions is used considering incoherence, wave passage and site effects. The generated time histories conserve the same energy at various points on ground surface of a random site and therefore are compatible with the homogeneity assumption of the site. The simulated spatial ground motions are also compatible with the prescribed model of coherency loss function. In the absence of data record, the generated time histories can be used as inputs to multiple supports of long span structures crossing random site.

\section{References}

[1] M. Walling and N. Abrahamson N, "Spatial coherency of ground motions for embedded structures". In. Proc. 4th International Conference on Earthquake Geotechnical Engineering, Thessaloniki, Greece, 2007.

[2] H. Hao and C. S. Oliveira and J. Penzien, "Multiple-station ground motion processing and simulation based on SMART1 array data," Nuclear Engineering and Design 111:293-310, 1989

[3] N. A. Abrahamson, "Generation of spatially incoherent strong motion time histories," Earthquake Engineering, Tenth World Conference, Balkema, Rotterdam, 1992, pp. 845-850.

[4] A. Zerva, "Spatial Variation of Seismic Ground Motions. Modeling and Engineering Applications," CRC Press, Boca Raton, 2009.

[5] P. G. Somerville, J. P. McLaren and C. K. Saikia, "Site-specific estimation of spatial incoherence of strong ground motion," in Proc. Earth. Engin. Soil Dyn. II, Recent Advances in Ground-Motion Evaluation, ASCE, Park City, Utah, $1988,188-202$

[6] N. Abrahamson, J. F. Schneider and J. C. Stepp, "Spatial coherency of shear waves from the Lotung, Taiwan largescale seismic test". Structural Safety, 10: 145-162, 1991.

[7] S. Santa-Cruz, E. Heredia-Zavoni and R. S. Harichandran, "Low-frequency behavior of coherency for strong ground motions in Mexico City and Japan," in Proc. 12 $2^{\text {th }}$ World Conference in Earthquake Engineering, Auckland, NewZealand, 2000, Paper No.76:1-8.

[8] H. Ding, Q. Liu, X. Jin and Y. Yuan, "Coherency function model of ground motion at base-rock," in Proc. 14th World Conference Earthquake Engineering, Vancouver, B.C., Canada, 2004, Paper No.2692

[9] K. AfifChaouch, B. Tiliouine, M. Hammoutene, R. Rupakhety and R. Sigbjörnsson, "Estimating ground motion incoherence through finite source simulation: a case study of the 1980 El-Asnam Earthquake," Bull. Earth. Eng.10: 1193-1204, 2016.

[10] K. Irikura, T. Kagawa and H. Sekiguchi, "Revision of the empirical Green's function method by Irikura (1986), Programme and Abstracts," The Seismological Society of Japan, 2: B25, 1997.

[11] K. Afif Chaouch, R. Rupakhety, S. Ólafsson, B. Tiliouine and M. Hammoutene, "Effects of stochastic soil layers on ground-motion incoherence: a case study in N.W. Algeria," in Proceedings of the 16th World Conference on Earthquake Engineering, Santiago, Chile, 2017.

[12] A. Zerva and T. Harada, "Effect of surface layer stochasticity on seismic ground motion coherence and strain estimates," Soil Dynamics and Earthquake Engineering 16: 445-457, 1997.

[13] A. Der Kiureghian, "A coherency model for spatially varying ground motions," Earth. Eng. Struc. Dyn. 25: 99-111, 1996.

[14] A. Hindy and M. Novak, "Pipeline response to random ground motion," Journal of Engineering Mechanics, ASCE, 106 (2): 339-360, 1980.

[15] P. C. Jennings, G. W. Housner and N. C. Tsai, "Simulated earthquake motions," Technical Report", Earthquake Engineering Research Laboratory, California Institute of Technology, Pasadena, CA, 1968.

[16] R. Rupakhety and R. Sigbjörnsson, "A note on autoregressive spectral estimates for frequency-wavenumber analysis of strong-motion array data," Bull Earth Eng, 11: 1279-1285, 2012.

[17] S. L. Kramer, “Geotechnical Earthquake Engineering,” Prentice Hall, Upper Saddle River, NJ, 1996. 